\begin{tabular}{lllllllllllllllllllllllllllllllll}
\hline$R$ & $E$ & $V$ & I & S & T & A & D & E & E & S & T & U & D & I & O & S & I & N & T & E & R & N & A & C & I & O & N & A & L & E & S
\end{tabular}

\title{
¿Es posible una visión renovadora para orientar el futuro de América Latina?*
}

José Miguel Insulza

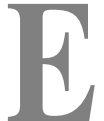

ste ciclo sobre América Latina, organizado por el Instituto de Estudios Internacionales de la Universidad de Chile, se realiza en un momento muy oportuno para abordar los grandes temas de nuestra región, puesto que nos encontramos -una vez más- en plena crisis. Y tal vez precisamente el hecho de estar enfrentando una nueva crisis, sobre todo en el plano económico, ha llevado a mucha gente a perder la fe en las posibilidades reales que tiene nuestro continente de abandonar definitivamente la marginalidad en el plano global.

Al ser esta charla la primera de una serie, me corresponde un papel casi introductorio. Pero resulta difícil establecer las principales características y espe- cificidades de la crisis que estamos viviendo y formular algunas propuestas para salir de ella. Y más aún cuando se espera que estas últimas sean alentadoras. Por otra parte, como se trata de un problema tremendamente complejo, cuyos orígenes dicen relación con la profundidad de la crisis misma, con la situación del conjunto de la región y también con la situación global en que se nos presenta, cuesta cumplir con el desafío de presentar una visión renovadora para enfrentar el futuro de América Latina y abordarla, además, con optimismo. Sin embargo, debo aclarar desde un comienzo que soy un latinoamericanista convencido y que, pese a las actuales dificultades, creo que América Latina tiene un destino y que Chile

* Conferencia dictada por el autor como parte del Ciclo de Conferencias "América Latina hoy en 12 preguntas y 120 sugerencias", organizado por el Instituto de Estudios Internacionales de la Universidad de Chile, que se realizó en la Facultad de Derecho de la Universidad de Chile del 3 al 29 de julio de 2002. 
podrá realizarse en mejor forma dentro de la región que al margen de ella. Después de mucho pesimismo, entonces, hacia el final de mi intervención intentaré esbozar algunas conclusiones en clave positiva.

\section{La percepción sobre América Latina en los años noventa fue más bien optimista.}

\section{Cambio de IMAGeN}

La percepción predominante sobre América Latina durante los años noventa fue más bien optimista, no obstante la crisis mexicana de mediados de la década y del consiguiente efecto tequila. De hecho, en ese período la región registró un crecimiento levemente superior al $2 \%$, cifra poco significativa comparada con aquella de los años sesenta y setenta, pero que no está nada mal si se considera que la correspondiente a la década perdida de los ochenta fue de (-) $1 \%$ y que algunos países -Chile entre ellos- experimentaron incluso caídas de dos dígitos en algunos años. Desde el punto de vista político, la década había presenciado la redemocratización de toda el área, el término de la guerra en Centroamérica y el avance de procesos integradores paralelos, siendo el principal de éstos el Mercosur, por la envergadura económica de sus dos socios principales y por lo auspicioso de sus principios. Finalmente, como el tequilazo concluyó mucho antes de lo que se esperaba, o en un ciclo más breve, se auguraba que al tomar las medidas adecuadas, nuestro continente iba quedando más a salvo de las crisis de origen económico.

Me pregunto si bastaron una crisis económica y el deterioro de la situación política que actualmente se vive en algunos países para cambiar tan radicalmente la imagen de progreso que se tenía a fines de los años noventa. Por desgracia, eso no fue suficiente, y principalmente por dos razones. Primero, porque la crisis abarca a casi todos los principales países de la región, entre los cuales sólo Chile y México parecen estar en condiciones estables, pese a haber experimentado también algunas turbulencias económicas caracterizadas por un lento crecimiento. La crisis económica de Argentina, las dificultades crecientes de Brasil y Uruguay, la inestabilidad política en Venezuela, el agravamiento de la guerra en Colombia, los problemas políticos recientes en Perú, no son situaciones que no hubiesen ocurrido antes. Sin embargo, nunca se habían presentado todas al mismo tiempo, y nunca habían puesto fin a un período auspicioso como el que siguió a la década de los ochenta, durante el cual se suponía que América Latina había retomado la buena senda. Es el conjunto, entonces, lo que ha generado una imagen de deterioro en nuestra región, suscitando temores de contagio expresados por algunos analistas internacionales que, curiosamente, son los mismos que hasta ayer sólo tenían elogios para las economías que hoy están en crisis.

Como decía, la crisis actual se presenta cuando este tipo de fenómenos se habían dado prácticamente por superados, 
después de haber adoptado todas las recetas indicadas para evitar que ocurrieran hechos similares. Por otra parte, con el fin del conflicto en Centroamérica y la llegada de la democracia a todos nuestros países, también se suponía que los conflictos políticos restantes avanzarían hacia la superación. No obstante, la guerrilla ha cobrado fuerza en Colombia, donde incluso han surgido grupos armados -los paramilitares- al otro lado del espectro, los conflictos étnicos han dividido a Ecuador y Perú, pese a haber superado la crisis Fujimori-Montesinos, no parece alcanzar una estabilidad política. Asimismo, Paraguay registra algunas incógnitas bastante serias para su futuro político.

La afirmación de que estábamos en otra etapa era aún más evidente en el plano económico, puesto que toda la región se había embarcado -con mayor o menor intensidad- en políticas de apertura económica, privatización de empresas, liberalización de mercados y reducción de tamaño del Estado. Para hacerse una idea de la profundidad que alcanzó este fenómeno, basta con recordar una sola cifra. Durante las negociaciones de la Ronda de Uruguay -en ese espacio de tiempo- los aranceles de los países de América Latina bajaron unilateralmente en un $50 \%$. Esto es, a la mitad, sin contar los acuerdos de la propia Ronda, ni el efecto de los acuerdos de libre comercio que dichos países firmaron. Sin duda, el evangelio de la modernización y de la apertura había llegado con fuerza a nuestra región. No es que alguien echara de menos -como pudo ocurrir en Europa- el Estado de bienestar. En realidad, los Estados latinoa- mericanos eran bastante más ineficaces, de manera que, en parte, continuaron sustentando burocracias ineficientes.

\section{El evangelio de la modernización y la apertura llegó con fuerza a la región.}

La liberalización, sin embargo, al no ir aparejada con altos índices de crecimiento -salvo en Chile y algunos años en Colombia y México- y con una superación significativa de la desigualdad y de la pobreza, sólo implicó más incertidumbre económica y política para los habitantes de la región. Así lo demostró Rodrik en un trabajo preparado para el Banco Mundial en 1999. Según esta investigación, un porcentaje significativo de la gente piensa que sus padres vivían mejor que ellos y, peor aún, que sus hijos vivirán todavía peor que ellos. Las cifras son distintas para el caso de Chile, donde la incertidumbre es mucho menor, aunque recordemos que el estudio se realizó en 1999, luego de diez años de crecimiento ininterrumpido. En alguna medida, entonces, Chile constituye una excepción: pese a las muchas dificultades, al país le ha ido bien con la globalización y la apertura. Otros, en cambio, todavía no logran recoger los frutos esperados y, en general, los que se encuentran en plena crisis culpan a la apertura de todas sus desgracias. En otras palabras, junto con la crisis existe un enorme sentimiento de frustración que se ha expresado, por ejemplo, en las protestas argentinas. La gente percibe que las cosas han caminado en una dirección contraria a lo deseado y que las reformas de 
los años noventa no rindieron los frutos previstos.

\section{Muchos piensan que sus padres vivían mejor que ellos y que sus hijos vivirán peor.}

También cabe considerar que el entorno dentro del cual se ha planteado hoy día la crisis latinoamericana es mucho más desfavorable que hace apenas algunos años. Hay una diferencia en lo ocurrido tras la crisis mexicana del 95 y los problemas posteriores en Asia y en Rusia, que fueron todos tanto o más graves que la actual situación de Argentina. En el caso de los primeros, se organizó una verdadera operación de rescate encabezada por Estados Unidos, en la cual participaron activamente los organismos internacionales de crédito. Lo mismo se hizo por Turquía, dada su enorme importancia estratégica y geopolítica como país de frontera entre el mundo islámico y el occidental, pero nada por Argentina. Y si bien es cierto este país fue víctima de sus propios errores y dificultades, también lo ha sido en parte de un nuevo estilo preexistente en estas materias, en virtud del cual se exigen alianzas estratégicas pero sin mucha disposición al rescate económico. Se trata de una característica anterior a los dramáticos hechos del 11 de septiembre de 2001, que se exacerbó después de ellos. Hoy día, Estados Unidos parece más dispuesto que nunca a liderar una alianza estratégica mundial, pero no a configurar un orden político e institucional capaz de proveer los bienes globales que el mundo y nuestra región necesitan. Dicho sea de otra forma, más de una década después del fin de la Guerra Fría, el sistema mundial continúa pareciéndose mucho al anterior, donde se privilegiaba lo estratégico por sobre lo económico y lo social. Con la gran salvedad de que ahora existe un orden unipolar en el cual los equilibrios no juegan papel alguno. América Latina debe enfrentar entonces un problema adicional a sus problemas económicos y políticos: por razones que no viene al caso discutir aquí, generalmente no se la considera un área estratégica, excepto cuando se presentan conflictos graves que es necesario atender puntualmente, como el caso de Cuba o de las drogas. En el resto, no es dable esperar demasiada cooperación.

\section{BARAJANDO ALTERNATIVAS}

Tenemos así un panorama bastante deprimente, que plantea riesgos nuevos e inminentes como producto de propuestas que, de concretarse, sólo conseguirían profundizar la crisis en nuestra región o sumirla aún más en la marginalidad. Y en este sentido, hay tres tentaciones que es preciso evitar: el aislacionismo, el apoliticismo y el populismo.

En cuanto a la primera, siempre es posible culpar a la globalización de todas las dificultades que América Latina ha enfrentado durante los últimos años. Pero si bien es cierto la globalización no representa necesariamente un juego de suma positiva para todos -es decir, en ella existen ganadores y perdedores, $\mathrm{y}$ al respecto 
recomiendo con entusiasmo El descontento con la globalización, de Joseph Stiglitz-, hoy día resulta muy difícil imaginar una salida al margen del proceso global y sin involucrarse en la economía y en la política mundiales. De manera que el aislacionismo que algunos predican como alternativa para superar los problemas -con frustración, guiados probablemente por la emoción más que por la razón-, sólo puede sumir a nuestros países en más miseria y en mayores dificultades. Existe incluso una forma de aislacionismo que consiste en marginarse de todos esos problemas: si Argentina y Brasil están en crisis -se dice- y en otras partes de la región existen dificultades, volvamos a separarnos de ellos. Por eso en la prensa han aparecido propuestas tales como salirse del Mercosur y una serie de cosas por el estilo. Pero como se verá más adelante, la realidad es que hoy día los estados que tienen el mismo tamaño del nuestro no pesan en el mundo ni en la economía global por sí solos. Lo más probable es que la búsqueda, o la quimera de forjar alianzas estratégicas sólidas y permanentes en otras regiones a expensas de la inserción en la propia, esté condenada al fracaso. Y más que al fracaso, a vivir en un ambiente generalmente poco fraterno y hostil que no conviene a ninguno de los involucrados.

\section{La falta de instituciones que funcionen agrava los problemas.}

Otra forma simplista de mirar la crisis es la respuesta del apoliticismo. Se- gún este punto de vista, la culpa no la tienen ni la globalización ni las recetas económicas, sino los políticos. En algunos países -y tengo la pretensión de pensar que en éste probablemente menos que en otros- esa crítica tiene algún mérito. Mal que mal, fenómenos como la corrupción y la esterilidad de los conflictos políticos han sido característicos de varios países de nuestra región. Pero incluso en los países donde esos problemas son más exacerbados, existe un factor adicional que los agrava: la falta de instituciones que funcionen. Al respecto, me parece interesante citar el caso de Argentina, donde el lugar común entre todos los que protes$\tan$ es que se lo robaron todo. No obstante, un estudio realizado por el Fondo Monetario reveló que en 1996 ese país recaudó menos de 50\% del IVA esperado. Si los argentinos hubieran pagado un $75 \%$ del IVA, en cambio, como lo hacen los chilenos o los uruguayos -porque tampoco en estos países se recauda el $100 \%$ del IVA- ese año Argentina no habría registrado un déficit fiscal. En otras palabras, pese al problema de las provincias, al exceso de personal en la administración pública y a la cantidad de dinero que probablemente salía por otras vías, una sola cifra demuestra que el problema institucional -el no funcionamiento de las instituciones- puede ser tan grave como los impasses y la corrupción en el sistema político.

Ciertamente, en América Latina la política necesita reformas, pero también es cierto que ése no es el fondo del problema. Por lo demás, gran parte de las soluciones de nuestro tiempo son políti- 
cas. Sin ir más lejos, el comercio entre Estados Unidos y México -no tanto con Canadá- era una realidad enorme desde hace muchos años, pero éste se potenció gracias a una acción política: la decisión de sus gobiernos de negociar el gran Acuerdo de Libre Comercio de América del Norte. También la Unión Europea es fruto de una acción política, detrás de la cual vinieron el comercio, la integración económica o los acuerdos productivos. Por lo tanto, el apoliticismo constituye una receta equivocada de quienes sueñan con un período durante el cual no funcionó la democracia en América Latina, pensando tal vez que en ese tiempo los problemas se resolvieron en mejor forma. Pero las cifras demuestran que pese a haber sido una década marcada por la anti política, durante los años ochenta se registraron índices de crecimiento inferiores a los que tuvo la región en todo el siglo pasado.

\section{Gran parte de las soluciones son políticas.}

El populismo también constituye una alternativa para salir de la crisis: volvamos al pasado, volvamos atrás, redistribuyamos lo que no existe. Resulta curioso ver que precisamente en las zonas donde el populismo causó mayor daño, que distribuyeron en lugar de ahorrar y que gastaron en lugar de crecer, hoy día se está promoviendo lo mismo. Basándose en una pasada grandeza o en una pasada riqueza, proponen resolver los problemas sobre la base de la distribución, sin enten- der la realidad de nuestro continente. Y la verdad es que, sin ser pobre, nuestra región es profundamente injusta, y sin ser débil, presenta grandes dificultades para crecer. Cuenta con los recursos necesarios para hacerlo, pero nunca ha tenido la organización ni la capacidad suficiente como para potenciar esos recursos en la dirección correcta a fin de obtener los beneficios esperados. Porque América Latina tiene sus fortalezas: se trata de una inmensa región con más de 400 millones de habitantes, donde existen más recursos, más capacidades intelectuales, más educación, más calidad de los recursos humanos y más integración cultural de lo que existe en la mayor parte de las naciones que han emprendido el mismo camino. A veces se habla de una América Latina casi quimérica, con tantos miles de kilómetros y grandes diferencias culturales y económicas. Pero nunca tantas diferencias culturales como las que existen entre un griego y un finlandés, y nunca tantas diferencias económicas como las que registraban España y Alemania hace apenas veinte años. Pese a los problemas, entonces, tiene fortalezas. Como decía, más que pobre es un continente mal organizado e injusto, que sólo puede realizarse en sí mismo. Por definición, toda integración efectiva es regional y condicionada geográficamente.

\section{RECETAS PARA SALIR DE LA CRISIS}

En cuanto a las medidas que recomendaría para enfrentar el futuro de América Latina, la primero es mantener una polí- 
tica abierta hacia la globalización. Tal como lo ha demostrado nuestro país, encerrarse en sí mismo no es la solución correcta. Gracias a su política de apertura internacional, Chile ha gozado de períodos ininterrumpidos de altos índices de crecimiento que no se habían registrado durante varias décadas.

\section{La globalización y la apertura no funcionan por sí solas.}

En segundo lugar, sin embargo, es necesario hacerse cargo de que la globalización y la apertura no funcionan por sí solas. Hemos vivido demasiado tiempo convencidos de que el mejor Estado es menos Estado, en circunstancias que éste juega un papel fundamental que no puede sustituir mano invisible alguna. Es el que determina una prioridad en los intereses nacionales, con vistas hacia el desarrollo y el crecimiento. También se preocupa de la justicia interna y de la distribución. Curiosamente, los partidarios de recurrir a las instituciones de la globalización nos golpean en la cara con los índices de competitividad mundial, encabezados por una nación como Finlandia, cuyo sector público genera más de $50 \%$ de su Producto Geográfico Bruto y que destina una cantidad enorme de recursos a la satisfacción de necesidades públicas y de bienes sociales públicos. Detrás viene Noruega, y recién en tercer lugar Singapur, con un Estado de tamaño más reducido. La apertura y la globalización sirven, es cierto, pero considerando un interés nacional basado en la política. Eso no lo tomó en cuenta América Latina durante la década anterior. Realizó una apertura casi a ciegas, convencida de que el mundo resolvería sus problemas sobre la base de una mano invisible, pero se equivocó. Y si bien es cierto que hoy día resulta imposible separarse de la globalización, porque no tenemos otro camino ni podemos darle la espalda, ésta debe mantenerse sobre la base de una gestión política en función de intereses nacionales.

Tercero, la necesidad de abordar la segunda ola de modernizaciones, y no me refiero solamente a la apertura de mercados y al libre acceso de capitales foráneos. Hay un conjunto de modernizaciones que dicen relación con las instituciones, cuya importancia resulta fundamental para enfrentar cualquier proceso, y sobre todo un proceso de crecimiento de la apertura económica. Durante los últimos años se han dado muchas recetas de crecimiento desmentidas por la última crisis. Se supone, por ejemplo, que para crecer es indispensable contar con una cantidad adecuada de recursos económicos, pero son contados los países que han tenido más recursos que Venezuela para realizar inversiones de capital. Por otra parte, ningún país latinoamericano se compara con Argentina en términos de cantidad de profesionales, científicos, ingenieros o estudios de posgrado. La educación, entonces, tal vez no sea un camino seguro para triunfar en la sociedad global. En la práctica, no lo son ni los recursos de inversión por sí solos, ni la educación por sí sola. Las recetas me hacen recordar las últimas 
elecciones presidenciales en Estados Unidos: cuando George Bush triunfaba en toda el área estratégica, Bill Clinton puso en su oficina un letrero que decía: "Es la economía, stupid". Ahora, yo diría que en América Latina son las instituciones. Nuestros países no tienen instituciones, instituciones en serio, que funcionen: una autoridad monetaria real, eficiencia en la recolección de tributos, un control adecuado de la gestión administrativa, un control adecuado de la probidad y sistemas judiciales que funcionen. Creo que ésta es precisamente la ventaja de nuestro país. Los chilenos no somos más creativos que el resto, nuestros empresarios no son más geniales y su población -pese a que a veces nos gusta pensarlo- no es la más educada de América Latina, pero Chile tiene instituciones que funcionan.

Por tanto, la cuarta sugerencia se refiere a generar instituciones económicas que funcionen. También una institucionalidad política entendida como verdadera democracia, sistemas de partido que efectivamente funcionen, romper con la asociación entre el sector privado y el público en la gestión política y terminar con el exceso de influencias de determinados sectores del capital privado sobre la gestión política, lo cual da un pluralismo real. En suma, una sociedad donde todo el mundo tenga los mismos derechos y el mismo acceso a la justicia. Eso es algo que hace mucha falta en América Latina, porque un ciudadano común y corriente no tiene acceso real al bien público de la justicia ni al ejercicio de sus roles.

\section{Un elemento muy central de la falta de estabilidad es la desigualdad.}

En quinto lugar, resolver el problema de la pobreza y la protección social de los ciudadanos. Para describir esta situación, siempre utilizo una palabra que se me quedó grabada hace muchos años, cuando vivía en México. Hubo un tremendo incendio, una tragedia originada por el estallido de unos balones de gas en el centro de la ciudad. Ahora, la pregunta fue qué hacían los balones de gas en el centro de la ciudad, y a raíz de eso un columnista cuyo nombre se me escapa escribió un texto en el diario Excelsior, titulada "El fuego del desamparo". Lo que nosotros debemos enfrentar en este continente es la brutal injusticia del desamparo en que viven millones de ciudadanos, que en Chile alcanza cerca de un $20 \%$ y que en otros lugares de la región llega al 40 ó $50 \%$. De ahí la frase que mencioné antes. "América Latina no es un continente pobre", dijo alguna vez Fernando Henrique Cardoso respecto de Brasil. Y es que Brasil no es un país pobre, pero sí injusto. Esta lacra latinoamericana, que nos sitúa en el último lugar del planeta -porque la desigualdad de América Latina es superior a la de cualquier otro lugar del mundo-, constituye ciertamente un elemento muy central de nuestra falta de estabilidad. Hoy día la pobreza no es ocultada, pero la riqueza y la desigualdad tampoco. En los campamentos o poblaciones marginales abundan las antenas de televisión, a través de las cuales la gente que no tiene nada mira a los que tienen todo. 
No existirá estabilidad en América Latina ni en ninguna otra región, pero sobre todo en América Latina, sin atacar este lamentable fenómeno característico de nuestra región que es la pobreza.

Sexto, enfrentar juntos y no separados los problemas de la globalización. Hoy día se habla de integración económica, pero entendemos algo distinto al concepto que se tenía hace unos treinta, cuarenta o cincuenta años atrás, cuando nació la integración. Seguramente, muchos recuerdan organismos como la ALADI o la ALALC, que yo llamaría instancias de integración complementaria: yo produzco las camisas y vendo las camisas en ambas partes, mientras tú produces los zapatos y puedes vender los zapatos acá. No era una integración competitiva, sino cerrada. En la actualidad, América Latina está obligada a incorporar el conjunto de sus capacidades para enfrentar la realidad de la globalización. Eso significa libre comercio, por cierto, pero sobre todo coordinar políticas económicas, coordinar esfuerzos y ampliar el espacio económico regional. Sin ampliar ese espacio -hasta ahora no ampliado, porque lo que tenemos todavía en nuestros países son principalmente acuerdos comerciales de ida y vuelta-, sin crear empresas multinacionales en el sentido real del término -es decir, que no correspondan a un solo país, sino a un esfuerzo por insertarnos en el conjunto de América Latina, porque eso es la verdadera integración-, nuestra región continuará manteniéndose en la marginalidad. Cada uno de nosotros, por separado, no cuenta con medios o capacidades suficientes como para competir por sí solos.

\section{Los organismos latinoamericanos de integración son esencialmente retóricos.}

De lo anterior se desprende una séptima receta, que sería, por cierto, fortalecer los organismos e instituciones de integración. Pero este tipo de mecanismos sólo alcanzarán su mayoría de edad cuando cuenten con instancias y sistemas de solución de controversias. Se dice que el Mercosur está en crisis. Cómo no va a estar en crisis, si carece de un sistema institucional que les permitiría a los países miembros abordar en conjunto sus grandes dificultades actuales. Comparado con la burocracia de Bruselas, el Mercosur es un enorme edificio en Montevideo, que está vacío. Generalmente toman sus acuerdos mediante llamadas telefónicas entre sus ministros y presidentes. No existen instancias adecuadas para resolver diferencias entre los integrantes del Mercosur, como lo sería, por ejemplo, un problema entre Chile y Uruguay por la exportación o importación de un determinado producto. Los organismos latinoamericanos de integración son esencialmente retóricos, de manera que el fortalecimiento obligatorio de la institucionalidad en términos de solución de controversias constituye un elemento muy central.

En octavo lugar, la necesidad de contar con una alianza militar y política para enfrentar la realidad mundial y pesar en ella. Hasta ahora nunca hemos pesado, porque no hemos tenido una política co- 
mún. En general, nuestras hipótesis y nuestras formas de pararnos ante el mundo nos han llevado a enfrentarnos entre nosotros mismos. Se dice que América Latina es estratégicamente poco interesante, pero digamos más bien que cada país de América Latina por sí solo es estratégicamente poco interesante. Los interesados en geopolítica, hagan el ejercicio de mirar el mapa y observen tan solo nuestro Cono Sur. Se trata de una región imponente, abierta hacia ambos océanos, donde se encuentran dos de las naciones más grandes del mundo. Tanto Brasil como Argentina están entre los diez países más grandes del mundo. Ciertamente, no constituye una zona menor desde el punto de vista geopolítico, ni deja de ser importante desde un punto de vista estratégico. Y me refiero solamente al Cono Sur de América, no a América Latina en su conjunto. Pero claro, si nuestra regla de oro es enfrentarnos siempre con el vecino, sin tener una política más allá, si nuestro involucramiento en política exterior consiste más que nada en un intercambio entre vecinos que puede mejorar o empeorar, sin mirar hacia el conjunto del mundo ni definir una política al respecto, ¿es posible pesar en la realidad mundial? Sin duda, la unidad política y estratégica de las naciones latinoamericanas constituye un elemento de primordial importancia, que necesariamente debería acompañar a la integración económica y a esta idea de enfrentar juntos y no separados los desafíos de la globalización.

\section{Cada país de América Latina por sí solo es estratégicamente poco interesante.}

Por último, la lucha por un mundo multipolar. Nosotros no tenemos nada que ganar con un mundo unipolar. Tal como lo han hecho en el pasado, cada nación de América Latina podría emprender una carrera para comprobar quién es el mejor aliado o quién se porta mejor. Pero también podemos optar -como lo proponía antes- por pararnos en nuestros propios pies, transformándonos en una efectiva fuerza internacional, con peso. Para ejercer ese peso, sin embargo, se requiere un mundo multipolar donde funcione la institucionalidad internacional, donde nadie imponga su propia ley -un sistema que funcione sobre la base del derecho y la comunidad de intereses-, donde proliferen los regímenes internacionales como formas de actuar en conjunto frente a intereses comunes. Ése es el mundo que nos conviene. Por lo tanto, una política exterior común de América Latina no debe promover a determinado bloque o determinado sector, sino un mundo multipolar.

Creo que Chile tiene muchos esfuerzos por hacer en estas materias y una gran posibilidad de formular propuestas. Mal que mal, gran parte de las cosas que he señalado no se aplican a nuestro país. Sin embargo, el hecho de que nos haya ido mejor que a otros no puede ser en caso alguno motivo de satisfacción, porque a nuestro país -como a todos- le va bien 
cuando a sus vecinos les pasa lo mismo. tros vecinos resuelvan sus problemas, que No hay frase más ingrata que aquélla pro- se pongan de pie, porque de esa forma les nunciada alguna vez por un jactancioso: irá mejor a ellos y, de paso, también a "Tenemos una excelente casa en un mal nosotros. Y en esa tarea, tal vez durante barrio". No existe una excelente casa en este ciclo podamos encontrar fórmulas un mal barrio: se desvalorizan igual. Lo menos generales que las que yo les he que a nosotros nos conviene es que nues- entregado. 